\title{
Three different ophthalmic presentations of juvenile xanthogranuloma
}

\author{
Henry HW Lau *, Wilson WK Yip, Allie Lee, Connie Lai, Dorothy SP Fan
}

This paper was presented as a preceding paper at the Asia Pacific Academy of Ophthalmology Congress 2011 at Sydney, Australia.

\section{A B S T R A C T}

Three cases of juvenile xanthogranuloma from two ophthalmology departments were reviewed. Clinical histories, ophthalmic examination, physical examination, investigations, and treatment of these cases are described. A 4-month-old boy presented with spontaneous hyphema and secondary glaucoma. He was treated with intensive topical steroid and anti-glaucomatous eye drops. The hyphema gradually resolved and the intra-ocular pressure reverted to $11 \mathrm{~mm} \mathrm{Hg}$ without any other medication. Biopsy of his scalp mass confirmed the diagnosis of juvenile xanthogranuloma. A 31-monthold boy presented with a limbal mass. Excisional biopsy of the mass was performed and confirmed it was a juvenile xanthogranuloma. A 20-month-old boy was regularly followed up for epiblepharon and astigmatism. He presented to a paediatrician with a skin nodule over his back. Skin biopsy confirmed juvenile xanthogranuloma. He had no other ocular signs. Presentation of juvenile xanthogranuloma can be very different, about which ophthalmologists should be aware of. Biopsy of the suspected lesion is essential to confirm the diagnosis.

\section{Hong Kong Med J 2014;20:261-3}

DOI: $10.12809 / \mathrm{hkmj} 134059$

${ }^{1}$ HHW Lau *, FRCS, FHKAM (Ophthalmology)

${ }^{1}$ WWK Yip, MB, ChB, FHKAM (Ophthalmology)

${ }^{2} \mathrm{~A}$ Lee, MB, BS

${ }^{1}$ C Lai, MB, BS, FHKAM (Ophthalmology)

${ }^{2}$ DSP Fan, FRCS, FHKAM (Ophthalmology)

${ }^{1}$ Department of Ophthalmology and Visual Sciences, Prince of Wales Hospital, Shatin, Hong Kong

${ }^{2}$ Department of Ophthalmology and Visual Sciences, The Chinese

University of Hong Kong, Hong Kong Eye Hospital, Hong Kong

* Corresponding author: henrylau@cuhk.edu.hk

\section{Introduction}

Juvenile xanthogranuloma (JXG) is a benign histiocytic skin disorder encountered primarily in infancy and childhood. Approximately 10\% of these patients exhibit ocular manifestations, whose presentations vary. Although patients can be asymptomatic, occasionally they have associated glaucoma and even blindness. ${ }^{1,2}$

\section{Case reports}

Case notes from 1 January 2008 to 31 December 2009 in two ophthalmology departments were reviewed. Three cases with a diagnosis of JXG were identified. The clinical histories, ophthalmic examination findings, physical examination, investigation results, and treatment of these patients are described.

\section{Case 1}

A 4-month-old boy with glucose-6-phosphate dehydrogenase deficiency was referred by a paediatrician because of right eye redness for 2 weeks. His antenatal and birth history was otherwise unremarkable. He had no recent history of eye injury. On examination, his right eye was diffusely injected, with a hazy right cornea and irregular pupil. There was a 1-mm organised blood clot in the anterior chamber of his right eye. No rubeosis was noted. Left eye examination was unremarkable, with a clear cornea and no hyphema. Fundal examination of the left eye was normal. The intra-ocular pressure (IOP) of right eye was $48 \mathrm{~mm} \mathrm{Hg}$ and in the left eye it was $14 \mathrm{~mm} \mathrm{Hg}$. In both eyes the corneal diameters (10.5 $\mathrm{x} 10 \mathrm{~mm}$ ) were normal for his age.

Blood tests-including complete blood picture, clotting profile, renal and liver function tests-were performed to rule out metabolic or haematological abnormalities, but yielded nil abnormal. Ultrasonography of his right eye showed a clear vitreous and the retina was flat without any intra-ocular mass. Magnetic resonance imaging of the brain and orbits was also performed, but revealed no intra-ocular mass. X-rays assessing his bones showed no features of non-accidental injury. The patient's medical and family history was noncontributory.

He was treated intensively with $1 \%$ topical prednisolone acetate (Pred Forte ophthalmic suspension USP, Allegan) 1 drop every hourly and anti-glaucomatous eye drops including $2 \%$ topical dorzolamide hydrochloride-timolol maleate ophthalmic solution (Cosopt; MSD) 1 drop twice 


\section{三個幼年性黃色肉芽腫病例不一樣的症狀 \\ 劉慶偉、葉偉權、李雅麗、黎匡怡、范舒屏}

本文報告兩所眼科中心遇到的三個幼年性黃色肉芽腫的病例，並描述 其臨床病史、眼科檢查、體檢、調查過程和處理方法。一名四個月大 的男孩出現自發性前房出血和繼發性青光眼, 為病人施以密集式的外 用類固醇和抗青光眼眼藥水。在沒有其他藥物的幫助下, 該前房血塊 逐漸消失, 眼內壓亦恢復至 $11 \mathrm{~mm} \mathrm{Hg}$ 。頭皮腫塊活檢證實病人患有 幼年性黃色肉芽腫。另一名31個月大的男孩出現角膜緣腫塊, 接受切 除手術後, 其活檢證實為幼年性黃色肉芽腫。最後是一名 20 個月大的 男嬰, 因先天性眼瞼贅皮和散光需要眼科的定期跟進。一名兒科醫生 發現他的背部有皮膚結節, 活檢後證實為幼年性黃色肉芽腫, 但這名 病人沒有其他眼部症狀。這三個病例顯示幼年性黃色肉芽腫的症狀表 現可以大不相同, 因此眼科醫生應該小心留意。如有懷疑, 活組織檢 驗可有助診斷。 daily and topical $0.03 \%$ bimatoprost ophthalmic solution (LUMIGAN; Allergan) 1 drop at night. The hyphema gradually resolved and IOP normalised (right eye, $14 \mathrm{~mm} \mathrm{Hg}$ ) without medication. No iris mass was noted after hyphema subsided. There was a skin nodule over the scalp but no other skin lesion was identified (Fig a). Biopsy of the scalp lesion yielded skin tissue with cellular intradermal expansion by histiocytes, which were uniform with small vesicular nuclei and foamy cytoplasm. The features were compatible with JXG.

The hyphema did not recur over the 2-year follow-up. His IOP remained normal (right eye $11 \mathrm{~mm} \mathrm{Hg}$ and left eye $15 \mathrm{~mm} \mathrm{Hg}$ ) without any medication. The latest visual acuity of both eyes was $20 / 30$.

\section{Case 2}

The second case was a 31-month-old boy who was born full-term with a normal birth weight $(2.7 \mathrm{~kg})$ and had normal development all along. He presented to us with an enlarging nasal limbal mass over the right eye. The mass had been noticed by his mother for 9 months. The patient was treated elsewhere with topical steroids and antibiotics but the lesion was unresponsive. Incisional biopsy of the lesion was performed and histopathology was reported to show 'inflammation'. Further increase in size of the lesion was noted after the biopsy. No other skin lesion was evident elsewhere. Ultrasound biomicroscopy of the right eye demonstrated a localised increase in thickness of the sclera at the site of the lesion with invasion into the cornea and the borders were illdefined (Fig b).

Using Kay Single Pictures, the unaided visual acuity of the right eye was 20/60 and of the left eye was 20/40. Examination under general anaesthesia was performed. There was a right-sided 6-mm limbal yellowish-grey mass over the nasal region with an adjacent lipid keratopathy of $1 \mathrm{~mm}$. The other eye anterior segment examination was unremarkable. The IOP (right eye $15 \mathrm{~mm} \mathrm{Hg}$ and left eye $14 \mathrm{~mm} \mathrm{Hg}$ ), corneal diameter $(12.5 \mathrm{~mm} \times 12 \mathrm{~mm})$, and fundal examination of both eyes were all normal.

The lesion was excised and a partial sclerectomy was performed. Bared sclera was covered by conjunctiva. Intra-operatively, the mass did not show any deep scleral involvement. After removal of the lesion, the bare area of the sclera was covered with a conjunctival graft. Histopathology sections showed a JXG comprising aggregates of histiocytes and Touton giant cells, situated in a fibrous stroma covered by non-keratinising squamous epithelium.

Postoperatively he was started on topical $1 \%$ prednisolone acetate ophthalmic suspension USP (PRED FORTE; Allergan) 1 drop 6 times daily and topical $0.5 \%$ levofloxacin (Cravit; Santen) 1 drop 4 times daily. Recovery was uneventful. Upon last follow-up 14 months after surgery, the best-
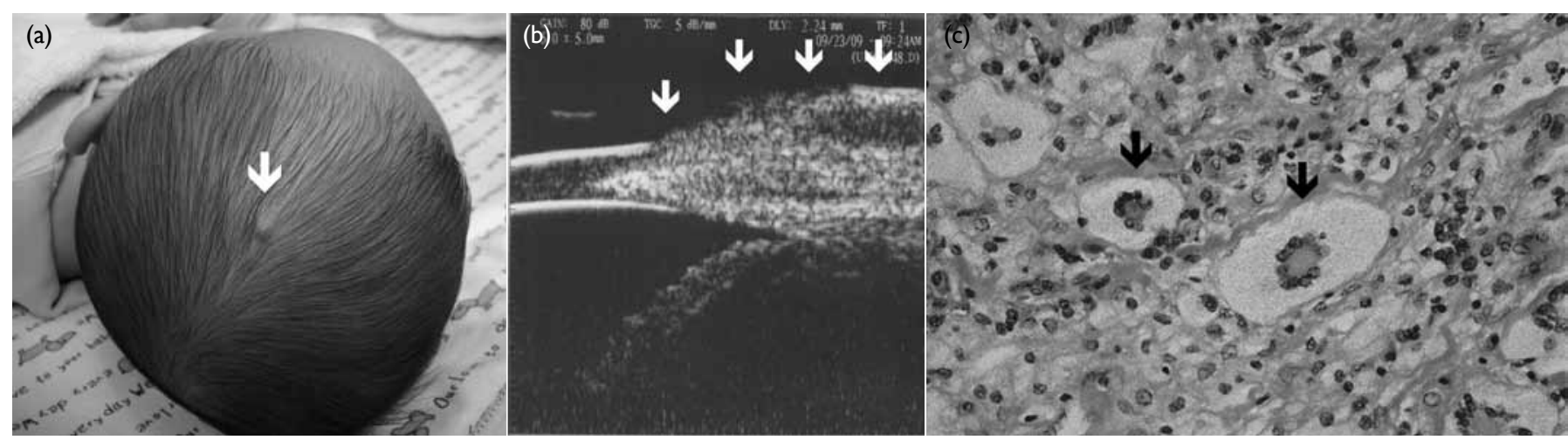

FIG. (a) Skin lesion (arrow) over the scalp of patient I. (b) Ultrasound biomicroscopy of the limbal mass of patient 2 demonstrates localised increase in thickness of the sclera with invasion into the cornea (arrows). (c) Skin lesion of patient 3 showing Touton giant cells (arrows), a feature of juvenile xanthogranuloma (H\&E, original magnification, $x$ 400) 
corrected visual acuity of both eyes was 20/20 with no evidence of recurrence.

\section{Case 3}

The third case was a 20-month-old boy who was regularly followed up because of epiblepharon. His unaided visual acuity of both eyes was 20/50. He also had astigmatism. Refraction of the right eye was -1.00 $\mathrm{D} /-1.00 \mathrm{D} \times 39$ and for the left eye it was $-1.00 \mathrm{D} /$ $-2.00 \mathrm{D} \times 157$. He presented to a paediatrician with a skin nodule over his back. Biopsy of the skin lesion yielded sections with bland epidermis. There was a well-demarcated nodule in the upper and lower dermis that was composed of histiocytes and foam cells, and a few Touton giant cells were seen (Fig c). These features were compatible with the diagnosis of JXG. He had no other ocular signs and symptoms including features of a hyphema or an ocular mass. Upon last follow-up 15 months after surgery, unaided visual acuity of both eyes was $20 / 50$ with no evidence of recurrence.

All three cases yielded a good visual prognosis and there was no recurrence of the disease.

\section{Discussion}

Ocular involvement is the most common extracutaneous manifestation of JXG. Risk factors for the development of eye diseases include the number of skin lesions, and being under 2 years old. ${ }^{3}$ This condition can affect the orbit, iris, ciliary body, cornea, and episclera, with the iris being the most commonly affected. ${ }^{4}$ Patients can present with iris nodules which can be quite vascular and may bleed spontaneously causing hyphema and secondary glaucoma. ${ }^{5}$

Zimmerman $^{1}$ first reported JXG. In his series of 53 infants and young children with JXG, he identified five presenting clinical features of intraocular involvement. ${ }^{1}$ This included an asymptomatic localised or diffuse iris tumour, unilateral glaucoma, spontaneous hyphema, red eye with signs of uveitis, and congenital or acquired iris heterochromia. However, JXG can sometimes be difficult to be diagnosed and can mimic melanomas in the eye. ${ }^{6}$

Ocular JXG can be diagnosed by a skin biopsy if typical skin lesions are present. However, absence of skin lesion cannot rule out JXG, because skin lesions often regress spontaneously. Fifty percent of patients never develop skin lesions and may first present to the ophthalmologist. ${ }^{7}$ Treatment depends on the presenting signs and symptoms. Topical steroids can be used for hyphema, and anti-glaucomatous eye drops can be used if there is secondary glaucoma. In the presence of an ocular mass or skin mass, biopsy of the suspected lesion is essential to confirming the diagnosis. Sometimes JXG does not warrant treatment. However, if extracutaneous involvement exists, surgery, chemotherapy, or radiotherapy may become necessary. ${ }^{8}$

In this case series, the presentation of JXG was very different in the three patients. Treatment modalities should be individualised and tailored for different clinical presentations. Ophthalmologists should be aware of the various ophthalmic presentations in JXG. For skin lesions and systemic signs and symptoms, we should collaborate with paediatricians and dermatologists to provide holistic patient care.

\section{Declaration}

No conflicts of interest were declared by the authors.

\section{References}

1. Zimmerman LE. Ocular lesions of juvenile xanthogranuloma. Nevoxanthoedothelioma. Am J Ophthalmol 1965;60:1011-35.

2. Mocan MC, Bozkurt B, Orhan D, Kuzey G, Irkec M. Juvenile xanthogranuloma of the corneal limbus: report of two cases and review of the literature. Cornea 2008;27:73942.

3. Chang MW, Frieden IJ, Good W. The risk intraocular juvenile xanthogranuloma: survey of current practices and assessment of risk. J Am Acad Dermatol 1996;34:445-9.

4. Chu AC. Juvenile xanthogranuloma. In: Champion RH, Burton JL, Burn DA, Breathnach SM, editors. Rook's textbook of dermatology. 6th ed. Oxford: Blackwell Science; 2004: 2323-5.

5. Vendal Z, Walton D, Chen T. Glaucoma in juvenile xanthogranuloma. Semin Ophthalmol 2006;21:191-4.

6. Fontanilla FA, Edward DP, Wong M, Tessler HH, Eagle RC, Goldstein DA. Juvenile xanthogranuloma masquerading as melanoma. J AAPOS 2009;13:515-8.

7. Howard J, Crandall A, Zimmerman P, et al. Juvenile xanthogranuloma of the iris of an adult presenting with spontaneous hyphema. Ophthalmic Pract 2001;19:124-9.

8. Hernandez-Martin A, Baselga E, Drolet BA, Esterly NB. Juvenile xanthogranuloma. J Am Acad Dermatol 1997;36:355-67. 